ORTHODONTICS; METABOLISM

\section{Craniofacial development in obese adolescents}

Sadeghrianrizi A, Forsberg C-M et al. Eur J Orthod 2005; 27: 550-555

Obesity appeared associated with more pronounced prognathisms and greater facial dimensions.

Genetic control accounts for about 1/3 of the variation in body mass index (BMI), a ratio of weight to height squared $\left(\mathrm{kg} / \mathrm{m}^{2}\right)$; BMI of 25 is defined as overweight, and 30 as obesity. In obese patients, growth hormone secretion is significantly reduced, and there are other possible differences which may also affect craniofacial growth. In this study, lateral cephalograms of 50 obese subjects were compared with those for matched normal controls.

In obese individuals, anterior cranial base, mandibular and maxillary lengths were all greater. Lower anterior and posterior face height and mandibular plane angle were also greater, as was maxillary dentoalveolar height. There were also certain genderspecific differences. The authors discuss the findings and conclude there may be a need to modify orthodontic treatment goals in obese individuals.

doi:10.1038/sj.bdj.4813259

\section{PERIODONTOLOGY; SMOKING CESSATION}

\section{The effect of quitting smoking on chronic periodontitis}

Preshaw PM, Heasman L et al. J Clin Periodonto/ 2005; 32: 869-879

Following smoking cessation, there was an added benefit to nonsurgical periodontal treatment.

Smoking markedly increases prevalence, severity and extent of periodontitis, and also reduces the effect of treatment. In this study, periodontitis was treated non-surgically in 49 smokers who wished to quit smoking. Individual smoking cessation counselling was provided. After 1 year, complete data were available for 26 subjects who were then divided into 3 groups according to quitting status. There were 10 definite quitters (Q), 10 definite non-quitters $(\mathrm{N})$, and 6 who oscillated between smoking and not smoking $(0)$.

Mean 1 yr probing depth reduction from baseline was 1.57 for $\mathrm{Q}$ group, 1.12 for $\mathrm{N}$ and 1.08 for $\mathrm{O}(\mathrm{P}<0.05$ for $\mathrm{Q}$ versus $\mathrm{O}+\mathrm{N})$. Mean probing attachment level remained unchanged in each group, though it appeared greater in Q throughout. Bleeding scores decreased following treatment in all groups, though without differences between groups. Plaque scores followed a similar trend. The authors consider the additional improvement in Q group may be a consequence of quitting smoking.
BIOMATERIALS; ORAL MEDICINE

\section{Changes in health over time in patients with symptoms allegedly caused by their dental restorative materials}

Tillberg A, Berglund A et al. Community Dent Oral Epidemio/ 2005; 33: 427-437

There was a subjective improvement in patients who had changed materials in all their restorations, but those with complex complaints became subjectively worse.

Though a few patients might experience an allergic response to amalgam components, there is no scientific evidence that mercury in amalgam restorations presents any significant health hazard. Despite this, there are patients who have had restorations replaced because they believe otherwise. Such patients have been found to differ psychologically from the general population.

At a Swedish dental school, 614 patients who had been examined over an 8 year period for alleged reactions to materials were sent a questionnaire, and 54\% responded. Compared with a random sample of the Swedish population, these subjects had significantly worse levels of 23 specified symptoms. Of all subjects, $41 \%$ had all restorations replaced, 36\% had some replaced, and 23\% had no replacement. These 3 groups did not differ significantly in having complaints at follow-up, although the total replacement group had more changes than the other groups. However, those who had complained of both local and general symptoms were more likely to have worse symptoms $(\mathrm{OR}=1.8 ; P=0.03)$ than the others.

doi:10.1038/sj.bdj.4813261

\section{CARIES; BEHAVIOURAL SCIENCE}

\section{Dental caries experience: a two generation study}

Bedos C, Brodeur J-M et al. J Dent Res 2005; 84: 931-936

Children of edentulous mothers were at greater risk of caries.

Early life is a critical period for behavioural programming, and studies have shown numerous psychosocial effects on dental diseases. In this study, a random sample of 9,930 mother-child pairs was approached, and 6,303 mothers completed a questionnaire and brought a child (aged 5-8 yrs) for interview and examination. A group of 264 edentulous mothers was identified and compared with 6,039 dentate mothers. The latter had lower mean age, greater mean family income and higher educational level, and tended to have younger children.

Mean dmfs was significantly lower in 5-, 7- and 8-yr-old children of the dentate mothers (e.g. 5.18 v. 8.48 at age $7 \mathrm{yrs}$ ), and more of this group of $8 \mathrm{yr}$-olds were caries-free in the permanent dentition (74\% v. $62 \%$ ). Multiple logistic regression showed significant odds ratios of 1.7 for greater deciduous dentition caries experience in children of edentulous mothers, and 1.4 for the permanent dentition.

doi:10.1038/sj.bdj.4813262 